\title{
SECM imaging of MMD-enhanced latent fingermarks $\dagger$
}

\author{
Meiqin Zhang, ${ }^{a}$ Andy Becue, ${ }^{b}$ Michel Prudent, ${ }^{a}$ Christophe Champod ${ }^{* b}$ and Hubert H. Girault*a
}

\author{
Received (in Cambridge, UK) 17th July 2007, Accepted 9th August 2007 \\ First published as an Advance Article on the web 17th August 2007 \\ DOI: $10.1039 / \mathrm{b} 710947 \mathrm{~d}$
}

\begin{abstract}
Scanning electrochemical microscopy (SECM) has been used to image latent fingermarks enhanced by adsorption of gold nanoparticles onto which silver is chemically deposited, a process known as "multi-metal-deposition" (MMD).
\end{abstract}

When a finger touches a surface, secretions are deposited leaving an impression of the finger's ridge pattern, referred to as a latent fingermark, which requires physical or chemical treatments to enable visualization. Fingermarks are still most widely used for personal identification. ${ }^{1}$ They provide valuable physical evidence of contact between a finger and a surface. For years, forensic scientists have been seeking new methods or trying to improve existing methods for the visualization of latent fingermarks. The structured combination of optical methods (diffused reflection, luminescence, UV absorption and reflection), physical methods (powdering, small particle reagent, vacuum metal deposition), physico-chemical methods (physical developer, multi-metal-deposition (MMD), iodine, cyanoacrylate) and chemical methods (ninhydrin and its analogues, DFO, etc.) permits a rational and highly efficient processing of the secretions deposited by the fingers on a great variety of substrates. ${ }^{2}$ To visualize these developed fingermarks, alternative light sources (such as Crimescope or Polilight) or laser-based detection methods are commonly used. However, these optical methods do not work in all possible cases, and certain types of latent fingermarks or object surfaces may be problematic. The major challenges in fingermark detection with laser techniques stem from both low emission levels from the fingermark secretions and interferences from the background signal, for example the background fluorescence when imaging a fingermark on bank notes. Up to now, no electrochemical imaging method has been reported to detect the latent fingermarks.

Scanning electrochemical microscopy (SECM), a scanning probe technique, has been developed into a powerful technique for the kinetic measurements of localized processes at solid-liquid or liquid-liquid interfaces, for high-resolution imaging of the chemical activity and/or topography of various interfaces on a localized scale, and for microfabrication. ${ }^{3}$ In SECM experiments, the probe is a noble metal microelectrode brought to the vicinity of the substrate surface, where the amperometric response (either for an oxidation or a reduction process) that depends on the

${ }^{a}$ Laboratoire d'Electrochimie Physique et Analytique, Ecole Polytechnique Fédérale de Lausanne, CH-1015 Lausanne, Switzerland. E-mail: hubert.girault@epfl.ch; Fax: +41-21-693 3667;

Tel: +41-21-6933145

${ }^{b}$ Institut de Police Scientifique, School of Criminal Sciences, University of Lausanne, Batochime, CH-1015 Lausanne, Switzerland.

E-mail: christophe.champod@unil.ch; Fax: +41-21-692 4605;

Tel: +41-21-692 4629

$\uparrow$ Electronic supplementary information (ESI) available: An optical laserscanner image of the original sample. See DOI: 10.1039/b710947d electrochemical reactivity of the substrate is recorded as a function of the lateral probe position $(x, y)$ for imaging. SECM is able to resolve differences on the micron or sub-micron length scale, an advantage which is clear in many reported applications. ${ }^{4}$ We have previously shown that SECM could be used in the feedback mode to image silver or copper stained proteins, by generating at the microelectrode an oxidizer to oxidize these metals. ${ }^{5}$ These reports proved the feasibility of using SECM for imaging protein spots on a membrane surface. Very recently, we have shown that SECM combined with silver staining could be applied to image proteinmodified fingermarks on a porous poly(vinylidene difluoride) (PVDF) membrane. ${ }^{5 d}$ Herein, we demonstrate that SECM can be used to obtain high-resolution images of real latent fingermarks enhanced by silver on gold MMD. This methodology takes advantage of the high sensitivity of SECM towards the small variation of electrochemical reaction rates at the substrate surface.

In this work, the samples developed by silver on gold MMD were prepared by following a procedure previously reported. ${ }^{6}$ Silver on gold MMD is based on the use of small particles of metallic gold (diameter $\sim 14 \mathrm{~nm}$ ) suspended in water and called "colloidal gold". Under specific experimental conditions, gold nanoparticles bind, mainly by electrostatic interactions, to the fingermark residues. Due to the small particle size, it is often difficult to optically observe the fingermarks at this stage. Consequently, a second step is required to enhance the contrast, i.e., the specific chemical deposition of metallic silver onto the gold particles. As a result, the finger deposits distinctly appear as black ridges on a lighter background. Silver on gold MMD is a very sensitive technique that is efficient on a wide range of surfaces, both porous and non-porous. In particular, it is a detection method that can be used on surfaces that are problematic with other conventional techniques, e.g. polystyrene packaging, thermal paper and surfaces that are or have been wet. Here, the fingermarks developed by the MMD technique are imaged electrochemically in the feedback mode, where the silver layer on the gold nanoparticles is re-oxidized upon the passage of the scanning probe.

A three-electrode setup was employed with a $20 \mu \mathrm{m}$-diameter Pt disk-shaped microelectrode as the amperometric SECM probe. The counter and quasi-reference electrodes were a Pt wire and a silver wire, respectively. The MMD-enhanced fingermark on a microscope glass slide was secured onto a platform which includes three screws for levelling the substrate surface. The operating principle for SECM imaging of MMD-enhanced latent fingermarks on the glass substrate is presented in Fig. 1. An approach curve, required to determine the distance between the probe and the substrate, was carried out with $1 \mathrm{mM} \mathrm{K}_{3} \mathrm{IrCl}_{6}+0.1 \mathrm{M} \mathrm{KNO}_{3}$ solution at a potential of $E_{\text {probe }}=0.8 \mathrm{~V}$ ( vs. Ag QRE) on a blank area of the surface, and was stopped when the probe touched the 


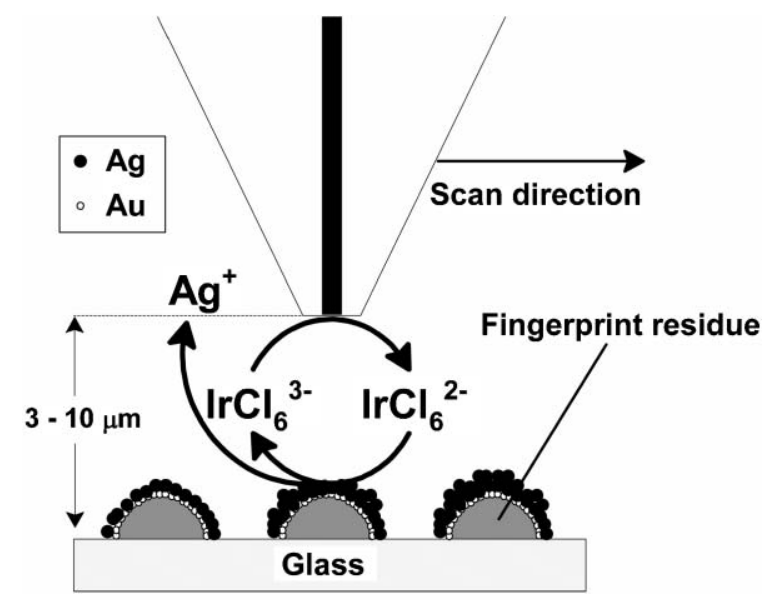

Fig. 1 Schematic (not to scale) diagram of the operating principle for SECM imaging of MMD-enhanced latent fingermarks on the glass substrate using $\mathrm{IrCl}_{6}{ }^{3-}$ oxidation $\left(E_{\text {probe }}=0.8 \mathrm{~V}\right.$ vs. $\left.\mathrm{Ag} \mathrm{QRE}\right)$ at the probe.

glass. The probe was then retracted about $4 \mu \mathrm{m}$ and coarsely positioned above the surface of the fingermarks for imaging. In the amperometric feedback mode, the probe signal used for imaging is a faradaic current, $i$, originating from the oxidation of the mediator $\mathrm{IrCl}_{6}{ }^{3-}$ added to the electrolyte solution. With the probe kept at a constant potential ( $0.8 \mathrm{~V} v s$. Ag QRE) high enough to oxidize $\mathrm{IrCl}_{6}{ }^{3-}$ and placed in the bulk solution far above the surface of the fingermarked substrate, a diffusion-limited steady state current $\left(i_{\infty}\right)$ is observed. When the probe is brought close to the black ridges of the MMD-enhanced fingermark sample, an electrochemical recycling of $\mathrm{IrCl}_{6}{ }^{3-}$ becomes possible by the following heterogeneous bimolecular electron transfer reaction between $\mathrm{IrCl}_{6}{ }^{2-}$ and silver particles: ${ }^{5 c, d}$

$$
\mathrm{Ag}(\mathrm{s})+\mathrm{IrCl}_{6}^{2-}(\mathrm{aq}) \stackrel{k_{\mathrm{ET}}}{\longrightarrow} \mathrm{Ag}^{+}(\mathrm{aq})+\operatorname{IrCl}_{6}^{3-}(\mathrm{aq})
$$

This process leads to an increase in probe current (positive feedback effect). On the other hand, the probe current decreases monotonically when it approaches the blank part of the substrate because of $\mathrm{IrCl}_{6}{ }^{3-}$ diffusion hindrance (negative feedback effect). Changes in the probe current during lateral scans used for "electrochemical imaging" reflect the topology of the MMDenhanced fingermark on the glass surface.

The feedback mode of SECM can be observed when the probe is close to the surface, usually at a distance less than twice the probe radius $r$. Theoretically, the spatial resolution of SECM is mainly governed by $r$, i.e., a smaller probe offers a higher spatial resolution, as the probe-substrate distance is reduced. This short distance, however, is difficult to maintain in the constant-height mode when SECM imaging large areas that may be tilted with respect to the travelling probe and probe crash can occur. Here, in order to image a relatively large area $(3 \mathrm{~mm} \times 2 \mathrm{~mm})$ of the fingermark with a high resolution, we chose a $20 \mu \mathrm{m}$-diameter probe and the probe-substrate distance was kept to about $4 \mu \mathrm{m}$. In addition, before SECM imaging, the sample surface was levelled manually as described in a previous report. ${ }^{5 d}$

An optical laser-scanner image of an MMD-enhanced fingermark on the glass substrate before SECM imaging is shown in
Fig. S1 (see ESI $\dagger$ ). The rectangular region marked (inside black line) corresponds to the area in Fig. 2a. The black and white lines represent the ridges and furrows, respectively. For comparison, two SECM images ( $3 \mathrm{~mm} \times 2 \mathrm{~mm}$ ) of this fingermark are shown
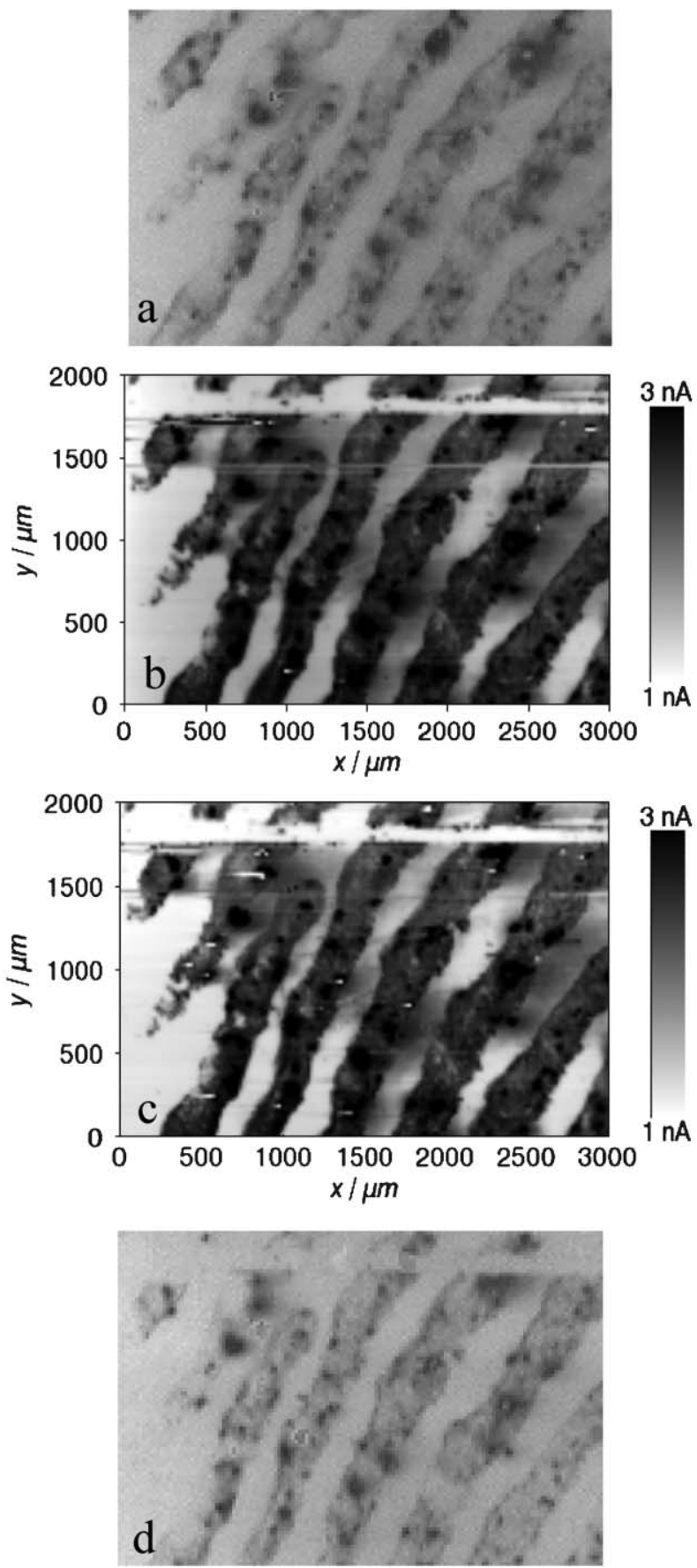

Fig. 2 (a) An optical laser-scanner image of a latent fingermark enhanced by MMD before SECM imaging. (b) A high-resolution SECM image $(3 \mathrm{~mm} \times 2 \mathrm{~mm})$ of sample Fig. $2 \mathrm{a}$ with a scan rate of $100 \mu \mathrm{m} \mathrm{s}^{-1}$. (c) A high-resolution SECM image $(3 \mathrm{~mm} \times 2 \mathrm{~mm})$ of sample Fig. 2a with a scan rate of $300 \mu \mathrm{m} \mathrm{s}^{-1}$. (d) An optical laser-scanner image of sample Fig. 2a after SECM imaging. Measuring conditions: $\mathrm{Pt}$ microelectrode with $20 \mu$ m-diameter as a SECM probe, $1 \mathrm{mM} \mathrm{K}_{3} \mathrm{IrCl}_{6}$ in $0.1 \mathrm{M} \mathrm{KNO}_{3}, E_{\text {probe }}=0.8 \mathrm{~V}$ vs. Ag QRE, a probe-substrate distance of approximately $4 \mu \mathrm{m}$. 
in Fig. $2 \mathrm{~b}$ and $2 \mathrm{c}$, which need about $5 \mathrm{~h}$ with respective scan rate of $100 \mu \mathrm{m} \mathrm{s}^{-1}$ and $300 \mu \mathrm{m} \mathrm{s}^{-1}$ to ensure the compatibility of the system with large surface scanning. The image area corresponds approximately to the same region as shown in Fig. 2a. The changes observed in SECM-generated data are mainly due to variations in the electrochemical reactivity between ridges that are covered with silver deposits and furrows that are not. In Fig. $2 b$ and $2 \mathrm{c}$, a dark colour has been used to emphasize the regions of significant positive feedback. The dark regions correspond to the ridges where silver clusters were deposited. The positive feedback is due to the regeneration of $\mathrm{IrCl}_{6}{ }^{3-}$ by the heterogeneous bimolecular electron transfer described in reaction (1). Inversely, the furrow regions of the fingermark cannot bind gold clusters onto the glass surface, so $\mathrm{IrCl}_{6}{ }^{3-}$ cannot be recycled. The insulating nature of microscopic glass blocks some of the diffusion of $\mathrm{IrCl}_{6}{ }^{3-}$ to the probe surface, which leads to a lower probe current as shown in the light regions of Fig. $2 \mathrm{~b}$ and $2 \mathrm{c}$. These data show that a fast scan rate of $300 \mu \mathrm{m} \mathrm{s}^{-1}$ provides a better resolution as the spreading of the diffusion field of $\mathrm{IrCl}_{6}{ }^{2-}$ is large at a low scan rate resulting in image blurring. Comparing with Fig. 2a, a white band is present in the region of $1.78 \leqslant y / \mathrm{mm} \leqslant$ 1.84 in Fig. $2 \mathrm{~b}$ and $2 \mathrm{c}$. This is due to the repeated line scans performed in the $x$ direction for levelling the substrate before SECM imaging, where metallic silver is completely dissolved in the solution. As can be observed in Fig. 2b and 2c, SECM of the MMD-enhanced fingermark provides images with a good contrast and a high resolution. An optical laser-scanner image of the same fingermark after SECM measuring is illustrated in Fig. 2d. A weak signal is shown in comparison with Fig. 2a due to the silver dissolution in SECM imaging. In addition, the white band observed in Fig. 2b and 2c also appears at the same position in Fig. 2d as expected.

In conclusion, a new approach for imaging latent fingermarks on a glass substrate is presented: fingermarks were first developed by the silver on gold multi-layer deposition method, and then revealed by SECM, with $\mathrm{IrCl}_{6}{ }^{3-}$ acting as redox mediator to detect the silver dissolution in the feedback mode. A highresolution SECM image $(3 \mathrm{~mm} \times 2 \mathrm{~mm})$ of a fingermark was achieved with a mediator concentration of $1 \mathrm{mM}$ and a scan rate of $300 \mu \mathrm{m} \mathrm{s}^{-1}$.
Work is in progress to extend this approach to image latent fingermarks on other surfaces, like paper, plastic or banknotes, which constitute surfaces of interest in forensic investigations. The main interest for the forensic community will be fingermarks deposited on textured or illustrated surfaces for which conventional optical techniques will lead to poor contrast.

This work was supported by Ecole Polytechnique Fédérale de Lausanne, the School of Criminal Sciences and Institute of Forensic Sciences, University of Lausanne. We also appreciate helpful discussions with Fernando Cortes Salazar (LEPA, EPFL).

\section{Notes and references}

1 (a) Fingerprints and other Ridge Skin Impressions, ed. C. Champod, C. Lennard, P. Margot and M. Stoilovic, CRC Press, Boca Raton, 2004; (b) Advances in Fingerprint Technology, ed. H. C. Lee and R. E. Gaensslen, CRC Press, Boca Raton, 2nd edn, 2001.

2 (a) G. Payne, B. J. Reedy, C. Lennard, B. Comber, D. Exline and C. Roux, Forensic Sci. Int., 2005, 150, 33-51; (b) G. S. Sodhi and J. Kaur, Forensic Sci. Int., 2001, 120, 172-176; (c) B. Schnetz and P. Margot, Forensic Sci. Int., 2001, 118, 21-28; (d) M. Sametband, I. Shweky, U. Banin, D. Mandler and J. Almog, Chem. Commun., 2007, 11, 1142-1144; (e) U. Ramminger, U. Nickel and B. Geide, J. Forensic Sci., 2001, 46, 288-293.

3 (a) Scanning Electrochemical Microscopy, ed. A. J. Bard and M. V. Mirkin, Marcel Dekker, New York, 2001; (b) P. Sun, F. Li, Y. Chen, M. Zhang, Z. Zhang, Z. Gao and Y. Shao, J. Am. Chem. Soc., 2003, 125, 9600-9601; (c) J. V. Macpherson, C. J. Slevin and P. R. Unwin, J. Chem. Soc., Faraday Trans., 1996, 92, 3799-3805; (d) S. Amemiya, J. D. Guo, H. Xiong and D. A. Gross, Anal. Bioanal. Chem., 2006, 386, 458-471; (e) G. Wittstock, M. Burchardt, S. E. Pust, Y. Shen and C. Zhao, Angew. Chem., Int. Ed., 2007, 46, 1584-1617; (f) J. Wang, F. Y. Song and F. M. Zhou, Langmuir, 2002, 18, 6653-6658; $(g)$ I. Turyan, T. Matsue and D. Mandler, Anal. Chem., 2000, 72, 3431-3435.

4 (a) B. Liu, S. A. Rotenberg and M. V. Mirkin, Proc. Natl. Acad. Sci. U. S. A., 2000, 97, 9855-9860; (b) I. Turyan, M. Etienne, D. Mandler and W. Schuhmann, Electroanalysis, 2005, 17, 538-542; (c) J. V. Macpherson, C. E. Jones, A. L. Barker and P. R. Unwin, Anal. Chem., 2002, 74, 1841-1848; (d) R. K. Zhu, S. M. Macfie and Z. F. Ding, J. Exp. Bot., 2005, 56, 2831-2838.

5 (a) M. Carano, N. Lion, J.-P. Abid and H. H. Girault, Electrochem. Commun., 2004, 6, 1217-1221; (b) M. Carano, N. Lion and H. H. Girault, J. Electroanal. Chem., 2007, 599, 349-355; (c) M. Q. Zhang, G. Wittstock, Y. H. Shao and H. H. Girault, Anal. Chem., 2007, 79, 4833-4839; (d) M. Q. Zhang and H. H. Girault, Electrochem. Commun., 2007, 9, 1778-1782.

6 B. Schnetz and P. Margot, Forensic Sci. Int., 2001, 118, 21-28. 